\title{
Specialist investigation of obscure gastrointestinal bleeding
}

\author{
J N THOMPSON, R R SALEM, A P HEMINGWAY, H C REES, \\ H J F HODGSON, C B WOOD, D J ALLISON, AND J SPENCER
}

\begin{abstract}
From the Departments of Surgery, Diagnostic Radiology, Pathology, and Medicine, Royal Postgraduate Medical School, Hammersmith Hospital, Ducane Road, London
\end{abstract}

SUMMARY The investigation and treatment of 131 patients with 'obscure' gastrointestinal bleeding has been reviewed. One hundred and six patients were assessed electively for recurrent haemorrhage, 25 presented as emergencies. The major presenting feature was melaena (55 patients), anaemia (35), rectal bleeding (34), haematemesis (six) and ileostomy bleeding (one). The lesions responsible for haemorrhage were colonic angiodysplasia (52 patients), small bowel vascular anomalies (16), Meckel's diverticula (nine), small bowel smooth muscle tumours (seven), gastric vascular anomalies (four), chronic pancreatitis (three), colonic diverticular disease (three) and 16 other miscellaneous lesions. No lesion was found in 21 cases. Lesions were first shown by visceral angiography (69 patients), at laparotomy (23), on endoscopy (11), on gastrointestinal contrast radiological studies (four), and at ERCP (three). Lesions which were undetectable at operation increased markedly with age $(\mathrm{p}<0 \cdot 0001)$. Expert visceral angiography is strongly recommended before surgery in patients over 45 years of age and after laparotomy when no cause has been found. Exploratory laparotomy is recommended at an early stage for younger patients, and for older patients after non-diagnostic angiography.

The cause of gastrointestinal haemorrhage is identified by routine investigations in about $95 \%$ of cases. $^{12}$ The remaining patients with 'obscure' gastrointestinal bleeding are frequently difficult to manage and often undergo extensive investigation and even laparotomy without diagnosis. The aim of this paper is to review the overall experience of the investigation of obscure gastrointestinal bleeding at this hospital, in particular to determine the method of diagnosis or localisation of haemorrhage and the relative incidence of different underlying conditions.

\section{Methods}

PATIENTS

Over a six year period 131 patients with obscure gastrointestinal bleeding were investigated at the Hammersmith Hospital. The large majority (87\%) were referred from other hospitals for specialist

Address for correspondence: Mr J N Thompson, FRCS, Department of Surgery, Royal Postgraduate Medical School, Hammersmith Hospital, Ducane Road, London W12 0HS.

Received for publication 2 May 1986. investigation, especially selective visceral angiography. The clinical details, investigations, surgical, and pathological findings in these cases were carefully examined. Some of these patients have been reported previously. ${ }^{34}$ Patients with previously diagnosed vasculitis and with gastrointestinal haemorrhage after recent surgery were excluded. The Fisher, $\chi^{2}$ and Mann-Whitney tests were used for statistical analysis.

\section{Results}

Seventy patients were men. The median age was 59 years (range 10-95). Twenty five presented with acute gastrointestinal bleeding, while 106 were investigated electively for recurrent gastrointestinal haemorrhage. The main presenting features were melaena (55 patients), anaemia (35), rectal bleeding (34), haematemesis (six) and ileostomy bleeding (one). The median duration of symptoms was 50 weeks (range one day-36 years). The median number of hospital admissions for gastrointestinal bleeding before referral to this hospital was two (range 0-21) with a median two previous blood 
transfusions (range 0-40). Twenty six patients had undergone previous surgery for gastrointestinal bleeding ( 20 patients - one operation, four patients - two operations, two patients - three operations). Seventy eight patients underwent surgery at this hospital $(64$ - one operation, 12 - two operations, one - three operations, one - four operations). The median total number of gastrointestinal investigations for each patient (excluding exploratory laparotomy) was six (range 2-27).

The probable cause of gastrointestinal bleeding and the initial method of diagnosis (or localisation) of identified lesions are shown in Table 1. In several patients more than one possible or actual cause for bleeding was found (see below), and patients have been classified by the lesion which at the time of review was thought to have been the most likely source of obscure haemorrhage. The nine 'other small bowel lesions' were a duodenal reduplication, an ulcerated duodenal diverticulum, a duodenal ulcer, an ulcerated jejunal diverticulum, ischaemic ulceration, an ulcerated ileal lymphoma, leukaemic small bowel involvement, secondary angiosarcoma deposits, and a solitary jejunal ulcer. The seven 'other colorectal lesions' were metastatic cholangiocarcinoma, a carcinoma of the caecum, an appendix tumour, a colonic adenoma, haemorrhoids (two patients), and a solitary rectal ulcer.

Radioisotope scans were carried out in 36 patients. Six patients with Meckel's diverticula had ${ }^{9}{ }^{9 m} \mathrm{Tc}$ technicate scans and these were negative in all cases. Technetium-99m labelled sulphur colloid or autologous red cells were used in 30 patients, and localised bleeding to the proximal small bowel in three patients, quantified daily blood loss in 12 patients, and were unhelpful in 15 patients.

Intraoperative selective visceral angiography was used to localise seven small bowel vascular lesions. Peroperative endoscopy was used in 16 patients, and identified vascular anomalies of the small bowel in four, and was helpful in determining the extent of colonic angiodysplasia in eight cases. Lesions were found in 21 of 27 patients undergoing laparotomy at this hospital after angiography which failed to identify a cause for bleeding, the majority of these lesions were in the small bowel.

The age, sex, major presenting feature, duration of symptoms, number of gastrointestinal investigations and number of patients undergoing surgery for each diagnostic group are shown in Table 2. Patients with Meckel's diverticula $(\mathrm{p}<0 \cdot 001)$ and smooth muscle tumours of the small bowel $(p<0 \cdot 01)$ were younger than all other patients, while those with angiodysplasia were older $(p<0 \cdot 01)$. The proportion of male patients with Meckel's diverticula was higher than for other lesions $(p=0 \cdot(05)$. The incidence of vascular anomalies (gastric, small or large bowel) was higher in patients aged 45 years and over $(<45$ years $-10 / 35$ patients, $>45$ years $-62 / 96$, $\mathrm{p}<0 \cdot 001)$. Patients with angiodysplasia presented more frequently with rectal bleeding $(p<0 \cdot 001)$ and less commonly with melaena $(\mathrm{p}<0.0001)$ than other patients, whereas those with vascular anomalies of the small bowel presented less frequently with rectal bleeding $(p<0 \cdot 05)$ but more commonly with melaena $(p<0 \cdot 001)$. Patients with small bowel vascular anomalies underwent laparotomy at any time more frequently than other patients $(p<0 \cdot 01)$,

Table 1 Cause of obscure gastrointestinal bleeding and method of initial diagnosis (or localisation) of identified lesions

\begin{tabular}{|c|c|c|c|c|c|c|c|}
\hline Diagnosis & $n$ & $(\%)$ & $\begin{array}{l}\text { Selective } \\
\text { visceral } \\
\text { angiography }\end{array}$ & Endoscopy & $\begin{array}{l}\text { GI } \\
\text { contrast } \\
\text { studies }\end{array}$ & $E R C P$ & Surgery \\
\hline \multicolumn{8}{|l|}{ Colonic } \\
\hline \multicolumn{8}{|l|}{ Small bowel } \\
\hline vascular anomalies & 16 & (12) & 9 & - & - & - & 7 \\
\hline Meckel's diverticula & 9 & (7) & 1 & - & 1 & - & 7 \\
\hline \multicolumn{8}{|l|}{ Small bowel smooth } \\
\hline muscle tumours & 7 & $(5 \cdot 5)$ & 6 & - & - & - & 1 \\
\hline Gastric vascular anomalies & 4 & (3) & 1 & 1 & - & - & 2 \\
\hline Chronic pancreatitis & 3 & (2) & - & - & - & 3 & - \\
\hline \multicolumn{8}{|l|}{ Colonic diverticular } \\
\hline disease & 3 & (2) & - & - & 2 & - & 1 \\
\hline Other small bowel lesions & 9 & (7) & 5 & 1 & - & - & 3 \\
\hline Other colorectal lesions & 7 & $(5 \cdot 5)$ & 2 & 2 & 1 & - & 2 \\
\hline Cause not identified & 21 & $(16)$ & - & - & - & - & - \\
\hline Total (\%) & 131 & $(100)$ & $69 *(53 \%)$ & $11(8 \%)$ & $4(3 \%)$ & $3(2 \%)$ & $23(18 \%)$ \\
\hline
\end{tabular}

${ }^{*}$ Nine patients showed active bleeding at angiography. 
Table 2 Analysis of all patients by diagnostic group

\begin{tabular}{|c|c|c|c|c|c|c|c|c|c|c|c|c|}
\hline Diagnosis & $\begin{array}{l}\text { Total } \\
\text { number }\end{array}$ & $\begin{array}{l}\text { Medic } \\
\text { lrang }\end{array}$ & $\begin{array}{l}\text { ian age } \\
\text { ge) }\end{array}$ & Male:female & $\begin{array}{l}\text { Median } \\
\text { duration } \\
\text { symptoms } \\
\text { (weeks) }\end{array}$ & & $\begin{array}{c}\text { sent } \\
\text { ture } \\
A\end{array}$ & $\begin{array}{l}{ }_{*}^{t i n g} \\
R\end{array}$ & $H$ & $\begin{array}{l}\text { Previous } \\
\text { surgery }\end{array}$ & $\begin{array}{l}\text { Surgery } \\
\text { at this } \\
\text { hospital }\end{array}$ & $\begin{array}{l}\text { Median } \\
\text { no. of } \\
\text { GI invest. }\end{array}$ \\
\hline $\begin{array}{l}\text { Colonic } \\
\text { angiodysplasia }\end{array}$ & 52 & $63 \cdot 5$ & $(19-95)$ & $31: 21$ & 50 & 10 & 17 & 25 & 0 & 8 & 24 & 5 \\
\hline $\begin{array}{l}\text { Small bowel } \\
\text { vascular anomalies }\end{array}$ & 16 & 60 & $(26-88)$ & $5: 11$ & 104 & 13 & 2 & 0) & 1 & 8 & 15 & 7 \\
\hline Meckel's diverticula & 9 & 20 & $(13-55)$ & $8: 1$ & 6) & 6 & 3 & 0 & () & 0 & 9 & 6 \\
\hline Small bowel smooth & & & & & & & & & & & & \\
\hline muscle tumours & 7 & 43 & $(26-61)$ & $2: 5$ & 110 & 5 & 2 & 0 & () & 1 & 7 & 8 \\
\hline Gastric vascular anomalics & 4 & $67 \cdot 5$ & $(58-73)$ & $2: 2$ & 44 & 3 & 0 & 0 & 1 & 1 & 4 & 8 \\
\hline Chronic pancreatitis & 3 & 48 & $(36-51)$ & $2: 1$ & 17 & 1 & 1 & 0 & 1 & 0 & 2 & 15 \\
\hline $\begin{array}{l}\text { Colonic diverticular } \\
\text { disease }\end{array}$ & 3 & 71 & $(50-72)$ & $2: 1$ & 110 & 0) & 0 & 3 & 0 & 0 & 2 & 5 \\
\hline Other small bowel lesions & 9 & 53 & $(16-71)$ & $4: 5$ & 31 & 6 & 2 & 0 & $0 \dagger$ & 2 & 6 & $5 \cdot 5$ \\
\hline Other colorectal lesions & 7 & 45 & $(35-73)$ & $3: 4$ & 100 & 1 & 2 & 4 & () & 0 & 4 & 5 \\
\hline Cause not identified & 21 & 67 & $(10-87)$ & $11: 10$ & 49 & 10 & 6 & 2 & 3 & 6 & 5 & 7 \\
\hline All pationts & 131 & 59 & $(10-95)$ & $70: 61$ & 50 & 55 & 35 & 34 & 6 & 26 & 78 & 6 \\
\hline
\end{tabular}

${ }^{*} \mathrm{M}=$ melaena, $\mathrm{A}=$ anaemia, $\mathrm{R}=$ rectal bleeding, $\mathrm{H}=$ haematemesis.

tplus one ilcostomy bleed.

while a smaller proportion of those with angiodysplasia of the colon $(\mathrm{p}<0 \cdot(05)$ and patients without an identified cause $(p<0 \cdot 05)$ underwent surgery.

Fourteen patients had two lesions which were (or might have been) responsible for gastrointestinal haemorrhage. Nine patients with angiographic evidence of angiodysplasia had second lesions found at laparotomy (four Meckel's diverticula, a jejunal vascular anomaly, an ulcerated duodenal diverticulum, a solitary ulcer of the jejunum, chronic pancreatitis, and Crohn's disease of the ileum). Six of these patients had the colonic angiodysplasia left in situ and the other lesion excised, but two have required further surgery for excision of angiodysplasia. Two other patients initially treated by right hemicolectomy for angiodysplasia later required surgery for bleeding from other gastrointestinal vascular anomalies (one gastric, one small bowel). Three other patients had double lesions none of which was a vascular anomaly. Twenty patients are known to have rebled after surgery at this hospital. Fourteen of these patients underwent initial surgery for vascular anomalies of the stomach, small or large bowel and a further patient had angiographic evidence of angiodysplasia. Three further patients (two with identified causes) rebled after initial investigation without surgery at this hospital.

All excised 'non-vascular' lesions were confirmed pathologically. Histology showed evidence of angiodysplasia in 19 of 28 resected colonic specimens (with barium injection of the mesenteric blood vessels after resection in 14). Seven vascular anomalies were confirmed histologically (three arteriove- nous malformations, two haemangiomas, one multiple phlebectasia, one telangiectasia) from 15 resected small bowel specimens. None of the gastric vascular anomalies was seen histologically.

There were four postoperative deaths, one patient who had no identified cause and had not undergone surgery rebled and died, and a further patient died of concurrent disease. The follow up data of the surviving patients are limited with a median follow up of six months (range (0-83). Of the 21 patients in whom no cause was found four had no further bleeding, three are known to have rebled (one death), two died postoperatively, and in 12 cases the follow up data are incomplete.

All patients were divided into four approximately equal groups by age (Table 3 ). The proportion that

Table 3 Incidence of lesions causing obscure gastrointestinal bleeding which were 'undetectable' at laparotomy

\begin{tabular}{|c|c|c|c|c|}
\hline Age & $\begin{array}{l}\text { Patients } \\
\text { (n) }\end{array}$ & $\begin{array}{l}\text { Operation } \\
\text { at any time }\end{array}$ & $\begin{array}{l}\text { 'Undetectable' } \\
\text { at surgery" }\end{array}$ & $\begin{array}{l}\text { Colonic } \\
\text { angio- } \\
\text { dysplasia }\end{array}$ \\
\hline$--\quad-$ & & $-\quad-$ & --- & $-\square$ \\
\hline$<45$ & 35 & 22 & 3 & 2 \\
\hline $45-59$ & 31 & 19 & 7 & 6 \\
\hline $60-69$ & 32 & 21 & 15 & 9 \\
\hline$>69$ & 33 & 20 & 18 & 9 \\
\hline All & 131 & 82 & 43 & 26 \\
\hline
\end{tabular}

*'detectable' compared with 'undetectable' lesions: $\chi^{2}=29 \cdot 5$ $(\mathrm{p}<() \cdot()()) 1)$. 
had undergone surgery (at any time) was similar for the different age groups $(61 \%$ to $66 \%)$; however, the number of these patients who had 'undetectable' lesions at operation - that is, lesions that would not have been detected at a careful laparotomy without the use of operative angiography or endoscopy, increased markedly with age $(p<0 \cdot 0001)$. Twenty six of $43(60 \%)$ such 'undetectable' lesions were colonic angiodysplasia, the remainder being vascular anomalies of the small intestine or stomach or of unidentified cause.

\section{Discussion}

The overall $84 \%$ success rate for the identification of the cause of obscure gastrointestinal bleeding in this series is high. ${ }^{5-8}$ Selective visceral angiography was the most valuable investigation, identifying the probable cause of bleeding in $53 \%$ of all patients (55\% of those undergoing angiography). While others have found angiography useful in these patients, ${ }^{9-11}$ some doubt its value, ${ }^{12}$ and these differing attitudes probably reflect variations in quality of angiography and experience in radiological interpretation. Angiodysplasia of the colon was the commonest cause found in this series $(40 \%$ of all patients). Although the correlation between colonoscopic and angiographic diagnosis of angiodysplasia appears fairly good, ${ }^{4}$ angiodysplasia may be easily missed at endoscopic examination. ${ }^{13} 14 \mathrm{We}$ prefer to use selective visceral angiography initially in most of these patients as it has the advantage that it can be readily undertaken during haemorrhage and may also localise non-colonic lesions.

The proportion of gastrointestinal vascular anomalies (including angiodysplasia) causing haemorrhage increased significantly with age, and in older patients visceral angiography was particularly valuable in localising lesions that might not have been detected at laparotomy (even with the use of peroperative endoscopic examination). Angiography carried out during active gastrointestinal haemorrhage results in successful localisation of bleeding in the majority of cases. ${ }^{8}$ Gastrointestinal bleeding frequently stops, however, before angiography is done, especially if transfer to another centre is required. Only $7 \%$ of our patients had evidence of active haemorrhage during angiography. The same problem arises with the use of radionucleide scanning to localise bleeding sites, although our experience with these is limited.

The age, sex and main presenting symptom may be useful guides to the likely source of obscure gastrointestinal bleeding. Thus two thirds of male patients in this series under the age of 30 years had Meckel's diverticula. While $80 \%$ of patients aged 60 years or over who presented with rectal bleeding had colonic angiodysplasia. Almost $50 \%$ of patients presenting with anaemia were found to have angiodysplasia, although this proportion was reduced to a third in those undergoing surgery. Melaena was a less helpful presenting symptom, no single cause accounting for more than $24 \%$ of cases.

In this series exploratory laparotomy detected $21 \%$ of the identified causes of bleeding and was particularly valuable in younger patients. Careful examination of the stomach, small and large bowel should be carried out in all cases where an initial abdominal exploration fails to identify a cause for obscure gastrointestinal bleeding. Several lesions in this series were discovered on repeat inspection or palpation. Intraoperative gastrointestinal endoscopy and peroperative angiography have proved useful in identifying vascular anomalies of the gastrointestinal tract and in determining their extent before resection in this and other series. ${ }^{15-17}$ We currently prefer to use a colonoscope passed through the mouth to examine the small bowel during operation, or per anum for inspection of the large bowel.

The incidence of colonic angiodysplasia (40\%) compared with diverticular disease $(2 \%)$ in this series is much higher than that seen in others ${ }^{8}{ }^{11}$ and may be partly because of patient selection before referral, particularly as diverticular bleeding is often heavier (thus necessitating early emergency surgery) and less commonly recurs. ${ }^{11}$ Nevertheless these findings support the view that angiodysplasia is the commoner cause of lower gastrointestinal haemorrhage. ${ }^{9} 1114$ Although diverticular disease usually affects the sigmoid and descending colon, diverticular bleeding may occur more frequently from the right colon. ${ }^{11} 18$ Angiodysplasia is almost invariably located in the caecum and ascending colon." 111920 Thus right hemicolectomy would appear the most appropriate procedure if no other cause for lower gastrointestinal bleeding can be found at an emergency laparotomy, and this policy would have removed the cause in $60 \%$ of such cases who underwent surgery in this series. Where localisation of lower gastrointestinal bleeding has not been possible before emergency surgery in a patient with diverticular disease of the left colon a subtotal colectomy may be preferred, although it carries a higher morbidity and mortality. ${ }^{11}$ Preoperative angiographic localisation of bleeding relieves the surgeon of these difficult intraoperative decisions and should be attempted whenever possible.

Histological confirmation of resected vascular anomalies was obtained in only $56 \%$ of cases in this series. The difficulties of showing such vascular anomalies histologically are well recognised, ${ }^{9} 1420$ but the more frequent use of special vascular 
injection techniques should increase pathological identification. ${ }^{21}$

The number of patients $(11 \%)$ in this series with two potential or actual causes for obscure gastrointestinal bleeding emphasises the need for caution in attributing haemorrhage to a radiologically or endoscopically identified lesion in the absence of active bleeding. Angiodysplasia of the caecum in particular appears to be common in the elderly ${ }^{90}$ and may be incidental to a second lesion, ${ }^{11}$ indeed $11(8 \%)$ patients in this series had a second possible cause for haemorrhage associated with angiodysplasia.

We have previously suggested that early careful laparotomy should be done in younger patients with obscure gastrointestinal bleeding, and that expert angiography (until it is more widely available) should be reserved for older patients and those who have had a previous laparotomy without identification of a cause of bleeding. ${ }^{3}$ Such a policy would have identified a cause in 19 of the 22 patients under 45 years of age $(86 \%)$ who underwent laparotomy in this series. Unless expert angiography is readily available, this policy would seem justified. Expert angiography may be expected to detect a cause in the majority of patients with obscure gastrointestinal bleeding, but the absence of an angiographic abnormality should not discourage the surgeon from performing an exploratory laparotomy, which identified a cause in over $75 \%$ of such cases in this and another series. ${ }^{6}$

\section{References}

1 Spiller RC, Parkins RA. Recurrent gastrointestinal bleeding of obscure origin: report of 17 cases and a guide to logical management. $\mathrm{Br} J$ Surg 1983; 70: 489-93.

2 Myers RT. Diagnosis and management of occult gastrointestinal bleeding: visualization of the small bowel lumen by fiberoptic colonoscope. Am Surg 1976; 42: 92-5.

3 Thompson JN, Hemingway AP, McPherson GAD, Rees HC, Allison DJ, Spencer J. Obscure gastrointestinal haemorrhage of small-bowel origin. $\mathrm{Br}$ Med J 1984; 288: 1663-5.

4 Salem RR, Wood CB, Rees HC, Kheshavarzian A, Hemingway AP, Allison DJ. A comparison of colonoscopy and selective visceral angiography in the diagnosis of colonic angiodysplasia. Ann R Coll Surg Engl 1985; 67: $225-6$.
5 Sheedy PF, Fulton RE, Atwell DT. Angiographic evaluation of patients with chronic gastrointestinal bleeding. Am J Roentgenol Radium Ther Nucl Med 1975; 123: 338-47.

6 Richardson JD, McInnis WD, Ramos R, Aust JB. Occult gastrointestinal bleeding: an evaluation of available diagnostic methods. Arch Surg 1975; 110: $661-5$.

7 Brand EJ, Sullivan BH, Sivak MV, Rankin GB. Colonoscopy in the diagnosis of unexplained rectal bleeding. Ann Surg 1980; 192: 111-3.

8 Nath RL, Sequeira JC, Weitzman AF, Birkett DH, Williams LF. Lower gastrointestinal bleeding: diagnostic approach and management conclusions. Am J Surg 1981; 141: 478-81.

9 Baum S, Athanasoulis CA, Waltman AC et al. Angiodysplasia of the right colon: a cause of gastrointestinal bleeding. AJR 1977; 129: 789-94.

10 Boley SJ, Brandt LJ. Colonic ectasias and lower intestinal bleeding. Hosp Pract 1982; 17: 137-44.

11 Welch CE, Athanasoulis CA, Galdabini JJ. Haemorrhage from the large bowel with special reference to angiodysplasia and diverticular disease. World J Surg 1978; 2: 73-83.

12 Brearley S, Ambrose NS, Silverman S, Hawker PC, Dorricott NJ, Keighley MRB. Obscure bleeding from the small bowel. Br Med J 1984; 289: 108.

13 Tedesco FJ, Griffin JW, Khan AQ. Vascular estasias of the colon: clinical, colonoscopic and radiographic features. J Clin Gastroenterol 1980; 2: 233-8.

14 Anonymous. Angiodysplasia [Editorial] Lancet 1981; ii: $1086-7$.

15 Hines JR, Stryker SJ, Neiman HL et al. Intraoperative angiography in intestinal angiodysplasia. Surg Gynecol Obstet 1981; 152: 453-60.

16 Fazio VW, Zelas P, Weakley FL. Intraoperative angiography and the localisation of bleeding from the small intestine. Surg Gynecol Obstet 1980; 151: 637-40.

17 Athanasoulis CA, Moncure AC, Greenfield AJ, Ryan JA, Dobson TF. Intraoperative localisation of small bowel bleeding sites with combined use of angiographic methods and methylene blue injection. Surgery 1980; 87: 77-84.

18 Casarella WJ, Kanter IE, Seaman WB. Right-sided colonic diverticula as a cause of acute rectal haemorrhage. $N$ Engl J Med 1972; 286: 450-3.

19 Allison DJ, Hemingway AP, Cunningham DA. Angiography in gastrointestinal bleeding. Lancet 1982; ii: 3()$-3$.

20) Sabanathan S, Nag SB. Angiodysplasia of the colon: a post-mortem study. J $R$ Coll Surg Edinb 1982; 27: 285-91.

21 Galdabini JJ. Case no 36-1974; Case records of the Massachusetts General Hospital. N Engl J Med 1974; 291: $569-75$. 